\title{
An Exploratory Analysis of the Correlates of Risk-Taking Propensity in Canadian Military Personnel
}

\author{
Jennifer E. C. Lee ${ }^{1}$, Ann-Renée Blais ${ }^{2}$ \\ ${ }^{1}$ Department of National Defence, Ottawa, Canada \\ ${ }^{2}$ Defence Research and Development Canada, Toronto, Canada \\ Email: jennifer.lee@forces.gc.ca
}

Received October $23^{\text {rd }}$, 2013; revised November $28^{\text {th }}$, 2013; accepted February $14^{\text {th }}, 2014$

\begin{abstract}
Copyright (C 2014 Her Majesty the Queen in Right of Canada, as represented by the Minister of National Defence. This is an open access article distributed under the Creative Commons Attribution-Non Commercial-No Derivatives 4.0 International License, which permits use, distribution, and reproduction in any medium for non-commercial purposes, provided the original work is unchanged and properly cited.
\end{abstract}

There has been growing interest in the impacts of combat exposure on behavioral health outcomes such as alcohol use, risky driving and smoking in research on military personnel in recent years. One psychological factor that may explain such outcomes is an individuals' risk-taking propensity. The present study thus examined the relationships of risk-taking propensity with demographic variables, deployment history, as well as a number of health and risk behaviors. Data collected as part of a comprehensive health survey in the Canadian Armed Forces (CAF) in 2008 and 2009 were analyzed. Participants included a sample of 2157 Regular Force members, stratified to reflect the Regular Force in terms of rank, sex, and deployment history. Using subscales of the Domain-Specific Risk Taking Scale (DOSPERT), participants' levels of risk-taking propensity in the health and safety and in the recreational domains were assessed. Results consistently pointed to the higher levels of risk-taking propensity among younger respondents and men. While non-commissioned members (NCMs) reported higher levels of health and safety risk-taking propensity than officers, officers reported higher levels of recreational risk-taking propensity than NCMs. Variation in health and safety, but not recreational risk-taking propensity was found by deployment history. Health and safety risk-taking propensity was associated with a number of health-compromising behaviors (e.g., poor eating habits, inconsistent helmet use, smoking, problem drinking), while recreational risk-taking propensity was associated with a number of health-enhancing behaviors (e.g., good eating habits, physical activity, never smoking). Results thus point to noteworthy variations in the correlates of risk-taking propensity by risk domain among military personnel.

Keywords: Risk-Taking Propensity; Risk Behavior; Lifestyle; Deployment; Health

\section{Introduction}

Whether in combat or training, risk is a fundamental part of military service (Killgore, Cotting, Thomas, Cox, McGurk, Vo et al., 2008). Hence, it may come as no surprise that a propensity to take risks has, in some instances, been regarded as a desirable attribute for military personnel (Momen, Taylor, Pietrobon, Gandhi, Markham, Padilla et al., 2010). However, this very propensity may also lead to a greater engagement in unsafe behavior (Killgore, Vo, Castro, \& Hoge, 2006) and, possibly, increased risk of injury and harm (RTI International, 2006). Recently, it has been suggested that the experiences of military personnel, particularly during combat, might influence their risk-taking behaviors once they return from deployment. This has been an area of significant interest to various military organizations (North Atlantic Treaty Organisation [NATO] Research and Technology Organisation [RTO] Task Group 164, 2012), in light of the growing evidence of increased risk behavior (e.g., substance use or risky driving) and rates of injury post-deployment (e.g., Bray, Pemberton, Lane, Hourani, Mat-

${ }^{*}$ The present paper, accepted on February $14^{\text {th }}, 2014$, is the final corrected version. tiko, \& Babeu, 2010; Hooper, Debakey, Bellis, Kang, Cowan, Lincoln et al., 2006; Jacobson, Ryan, Hooper, Smith, Amoroso, Boyko et al., 2008; Kelley, Killgore, Athy \& Dretsh, 2010; Killgore et al., 2008; Thomsen, Stander, McWhorter, Rabenhorst \& Milner, 2011; Zamorski \& Kelley, 2012). In one analysis, however, Thomsen et al. (2011) observed that the effect of deployment on increased risk behavior was only significant among individuals with a history of engaging in risk behavior. Such findings raise the question of whether individuals with a predisposition towards risk behavior are particularly vulnerable to the effects of deployment.

\section{Risk-Taking Propensity and Military Deployment}

The idea that individuals inherently differ in their tendencies to engage in risk behavior is supported by both theory and empirical findings on risk-taking. Indeed, research has pointed to a high degree of inter-correlation among different types of risk behavior (Donovon \& Jessor, 1985; Jessor, Donovon, \& Costa, 1991), suggesting that these may share common psychosocial determinants (e.g., perceived environment or personality). Reflecting one's natural inclination towards taking risks, risk- 
taking propensity could play a role in this regard.

Risk-taking propensity may represent or result from a combination of personality traits that predispose individuals to engage in risk behaviors. To be sure, research has shown that individuals differ in their generalized attitudes towards risk, or risk attitudes, on a continuum from risk aversion to risk seeking, and that these may subsequently influence the process of risky decision-making (Blais \& Weber, 2009). In addition to risk attitudes, a wide range of personality factors have been thought to increase one's propensity to engage in risk behavior. Examples may include perceived invincibility (i.e., one's perception of being immune to the negative consequences associated with a given risky behavior), sensation seeking (i.e., the degree to which one enjoys and seeks out thrilling or exciting experiences) or impulsivity (i.e., the tendency to act in haste, with little thought) (Cherpitel, 1993; 1999; Kelley et al., 2010; Killgore et al., 2008).

Along with risk behaviors, such as alcohol use, drug use and smoking, there is evidence that risk-taking propensity increases among military personnel after deployment (Kelley, Athy, Cho, Erickson, King, \& Cruz, 2012). Kelley et al. (2012), for example, found that perceived invincibility as well as risk-related self-confidence and risk/thrill seeking evaluations significantly increased in US soldiers from pre-deployment to post-deployment. Over the same period, both frequency of alcohol use and risky driving practices (i.e., failure to wear a motorcycle helmet) increased. While acknowledging that risk-taking propensity may serve as a determinant of being deployed in the first place (Bell, Amoroso, Wegman, \& Senier, 2001), some authors have posited that increases in risk-taking propensity post-deployment reflect underlying changes in health and well-being (Killgore et al., 2008; NATO RTO Task Group 164, 2012). Killgore et al. (2008) argued that physical trauma or prolonged exposure to emotional stressors during deployment may have impacted regions of the brain, resulting in altered decision-making under risk. Results of one study demonstrated that US soldiers who screened positive for post-traumatic stress disorder (PTSD) with or without mild traumatic brain injury (mTBI) after returning from a deployment to Iraq, reported greater risk/thrill seeking than those who screened negative. These soldiers also demonstrated a more pronounced increase in risk-related selfconfidence evaluations (e.g., greater assuredness and preference for danger) from pre-deployment to post-deployment relative to soldiers who screened negative (Kelley et al., 2012). In their review, Zamorski and Kelley (2012) suggested that personality characteristics, such as having a high tolerance for risk, a tendency to seek sensational or novel experiences and being impulsive, might explain increases in risky driving behaviors among military personnel post-deployment. Along this line, risk-taking propensity could serve as a factor explaining the impact of deployment on risk behaviors.

Aside from having been found to increase after deployment (e.g., Killgore et al., 2008; Kelley et al., 2012), risk-taking propensity has been found to be significantly associated with risk behavior in some studies of US military personnel. Specifically, Killgore and his colleagues found that various measures of risk-taking propensity, such as the Evaluation of Risks (EVAR) scale and the Invincibility Beliefs Index, were associated with greater engagement in behaviors such as consuming alcohol, binge drinking, getting angry or yelling at others, getting into fights, and threatening others (Killgore, Castro, \& Hoge, 2010a; Killgore, Kelley, \& Balkin, 2010b).

\section{Domain-Specificity of Risk-Taking Propensity}

Among the various measures that have been used as indices of risk-taking propensity in military personnel research (e.g., Evaluation of Risks scale, Brief Sensation Seeking scale, Invincibility Beliefs Index; Kelley et al., 2010; Killgore et al., 2008), none were designed to account for possible differences in risktaking propensity across domains. Yet, individuals' risky choices (and hence their associated risk attitudes) have been found to vary across different domains and situations (MacCrimmon \& Wehrung, 1986, 1990; Schoemaker, 1990). Domains in which individuals have typically displayed different degrees of risk-taking include gambling, financial investing, business decisions, and personal decisions (MacCrimmon \& Wehrung, 1986, 1990). Personal decisions can be further broken down into sub-categories, which differ in their associated concerns and goals (Weber, Ames, \& Blais, 2005; Weber \& Lindemann, 2007), such as ethical (e.g., plagiarizing a term paper), health/ safety (e.g., unprotected sex), and social (e.g., confronting a coworker) decisions.

Inspired by the domain-specificity of risk attitudes, Weber, Blais, and Betz (2002) developed the Domain-Specific RiskTaking (DOSPERT) Scale-a 40-item self-report instrument that evaluates risk attitudes (as well as perceived-risk attitudes, i.e., the tradeoff between perceived risks and benefits) in six domains (i.e., ethical, gambling, health, investing, recreational, and social). Researchers have used the 2002 DOSPERT in a wide range of settings, populations, and cultures. For example, Harrison, Young, Butow, Salkeld, and Solomon (2005), in their review of a large number of instruments assessing risk propensity in healthcare decisions, alluded to the 2002 DOSPERT as one of three instruments that are "relevant to a clinical environment as they directly measure risk propensity across a number of everyday situations, including the propensity to take health-related risks" (p. 1394). Supporting the validity of the 2002 DOSPERT scores, Hanoch, Johnson, and Wilke (2006) showed that individuals who engaged in risky recreational activities (i.e., bungee jumpers, sky divers, hang gliders, and scuba divers) had the highest scores on the recreational risk- taking propensity subscale. As well, individuals who engaged in health seeking behaviors (i.e., gym members) and health risk behaviors (i.e., smokers) each had the lowest and highest scores, respectively, on the health and safety risk-taking propensity subscale.

\section{Study Objectives}

In light of recent work pointing to the domain-specificity of risk-taking propensity, the aim of the present study was to explore the correlates of risk-taking propensity in different domains among military personnel. For this purpose, analyses were carried out on data collected as part of a comprehensive health survey in the Canadian Armed Forces (CAF). In addition to assessing a wide range of health and lifestyle factors, this survey assessed health and safety, as well as recreational domains of risk-taking propensity using elements of the DOSPERT. Hence, it was determined whether risk-taking propensity in both domains varies as a function of various demographic variables and deployment history. As well, the relationships of both domains of risk-taking propensity with engagement in risk behaviors (e.g., substance use, smoking) and health behaviors (e.g., eating habits, physical activity, safety practices) were 
examined. Based on previous research, it was expected that risk-taking propensity would be greater among CAF personnel who were recently deployed. It was also expected that higher risk-taking propensity would be associated with greater engagement in risk behavior and, conversely, lesser engagement in health behavior.

\section{Method}

\section{Participants}

Participants were respondents of the 2008/9 Health and Lifestyle Information Survey (HLIS). This paper and pencil survey was mailed between November 2008 and November 2009 to a sample of 4744 CAF Regular Force members, which was stratified by rank, sex and deployment history to reflect the overall CAF Regular Force population. Among the 4744 CAF members who were mailed a survey, 2315 provided a response for a gross response rate of $49 \%$. An inverse proportional weight was applied to account for the stratified complex sampling design based on sex, rank and deployment history, after adjusting for non-response. Because some respondents did not provide enough information to be assigned a population weight, the final sample included 2157 members of the CAF Regular Force. With population weights applied, participants were primarily male (87\%), under the age of 40 years (28\% was 18 to 29 years, $28 \%$ was 30 to 29 years) and of lower ranks (51\% was Private/Ordinary Seaman to Master Corporal/Master Seaman). Also, most of them had been deployed in the past two years (76\%). More detailed information about the survey procedure is provided elsewhere (see Whitehead \& Hawes, 2010). The survey was approved by an independent human research ethics review board.

\section{Measures}

Consisting of multiple sections (e.g., overall health status, mental and social wellness, and occupational health and safety issues, among others), the 2008/9 HLIS was designed to provide a comprehensive assessment of health and its various determinants in the CAF. Details regarding the items or measures used to assess variables of relevance to the present study are provided below.

Risk-taking propensity. Risk-taking propensity was assessed using two 6-item subscales of the DOSPERT-recreational risk-taking propensity and health and safety risk-taking propensity. Items in these subscales represent various types of risky activities. Risky recreational activities include:

- Going camping in the wilderness

- Going down a ski run that is beyond your ability

- Going white water rafting at high water in the spring

- Taking a skydiving class

- Bungee jumping off a tall bridge

- Piloting a small plane

Risky health and safety activities include:

- Drinking heavily at a social function

- Engaging in unprotected sex

- Driving a car without wearing a seat belt

- Riding a motorcycle without wearing a helmet

- Sunbathing without sunscreen

- Walking home alone at night in an unsafe area of town

Using a 7-point rating scale $(1$ = extremely unlikely, 2 = moderately unlikely, 3 = somewhat unlikely, $4=$ not sure $5=$ somewhat likely, 6 = moderately likely, 7 = extremely likely), respondents indicated the likelihood with which they would engage in each activity if they had an opportunity to do so. The subscales demonstrated adequate reliability (i.e., Cronbach's alphas of .68 for the recreational and .80 for the health and safety risk-taking propensity subscales, respectively).

Demographic characteristics. Demographic variables that were considered included age group (18 - 29 years, 30 - 39 years, 40 - 49 years, 50 - 64 years), education (some/completed secondary, completed college/some university, completed university), element (air, sea, land), first official language (English, French), rank (non-commissioned member [NCM] or officer) and sex.

Deployment history. A variable was created to identify the number of times each participant was deployed in the past two years, based on responses to two items. Specifically, categorization was derived from responses to: 1) "When were you last deployed overseas?" and 2) "How many times have you been deployed overseas in the past 2 years?” Participants who answered "I've never been deployed" or "More than 2 years ago" to the former question, were categorized as having been deployed overseas 0 times in the past two years, while participants who indicated that they were deployed "In the last 12 months" or "Between 12 and 24 months ago" were assigned the values they provided to the latter question. While this variable did not take into consideration the duration or nature of the deployment, previous analyses revealed that $76 \%$ of the reported overseas deployments were in Afghanistan and 18\% were in the Middle East (Whitehead \& Hawes, 2010).

Health and risk behaviors. A broad array of health and risk behaviors was assessed in the 2008/9 HLIS, ranging from eating habits to the use of energy supplements. In the interest of parsimony, only a subset of behaviors was considered in the present study. As a starting point, variables were selected on the basis of their face validity as indicators of risk behavior. However, it was decided to also investigate the relationships of risk-taking propensity with health behaviors, since a greater propensity for risk-taking could also result in a decreased engagement in health behaviors. Therefore, some health behaviors were selected. In addition to face validity, the reliability of the measures (as determined through past research) was considered in the selection of variables. Broadly speaking, health and risk behaviors pertained to diet, physical activity, safety practices, and substance use.

To examine diet, questions assessed the number of times that respondents had skipped breakfast, skipped lunch, and felt too rushed to eat regular meals in the past week. Daily fruit and vegetable consumption was also assessed using a measure adapted from one used in the Canadian Community Health Survey (CCHS; Statistics Canada, 2001), which has been found to significantly correlate with the Healthy Eating Index (Garriguet, 2009). This measure requires respondents to report the frequency (daily or weekly) with which they consume six different types of fruits or vegetables (e.g., fruit juices, green salad, carrots). An index of daily frequency of fruit and vegetable consumption is then derived based on responses.

Physical activity was measured using another measure adapted from the CCHS (Statistics Canada, 2001). Total daily energy expenditure (EE) was estimated based on the frequency (number of times) and average duration (1 - 15 minutes, 16 - 30 minutes, 31 - 60 minutes or more than one hour) of respondents' participation in 18 activities. Respondents were categorized as 
inactive, moderately active or active according to pre-specified cutoff values (Statistics Canada, 2005; total EE of less than 1.5 for inactive, total EE of 1.5 to 2.9 for moderately active and total EE of 3 or more for active).

Bicycle helmet use was examined as an indicator of safety practices. Respondents were asked to report the frequency with which they wear a helmet when riding a bicycle (always, most of the time, rarely, never, don't ride a bicycle). Respondents who indicated that they did not ride a bicycle were excluded from any analysis involving this question.

Regarding substance use, respondents were asked to indicate whether or not they had used energy drinks (such as Red Bull, Full Throttle, Monster, AMP, Jolt or Wired) and performance enhancers (such as synephrine, glutamine, Co-enzyme Q10, amino acids, creatine, pro-hormones, hydroxymethyl butyrate/ $\mathrm{HMB}$ ) in the past year.

Smoking status was assessed based on two questions: whether respondents have smoked at least 100 cigarettes (4 to 5 packs) in their lifetime, and whether they currently smoke cigarettes every day, occasionally or not at all. Respondents who indicated that they had not smoked 100 cigarettes in their lifetime were considered never smokers. Among respondents who had smoked more than 100 cigarettes, those who indicated that they currently smoke every day or occasionally were considered smokers, while those who indicated that they currently do not smoke at all were considered ex-smokers.

Two indicators of alcohol use were examined: whether respondents had engaged in binge drinking (six or more drinks on one occasion) in the past year (less than monthly versus on a monthly basis or more), and their scores on the Alcohol Use Disorders Identification Test (AUDIT). Scores on the AUDIT range from 0 to 40 and reflect one's frequency of alcohol use, engagement in hazardous drinking and symptoms of possible alcohol dependence. Scores of 8 or more are recommended indicators of hazardous and harmful alcohol use (Babor, Higgins-Biddle, Saunders, \& Montneiro, 2001).

\section{Analyses}

All analyses were carried out using the SPSS 17.0 Complex Samples module, which allowed the adjustment for effects due to the stratified sampling design. A series of analyses of variance (ANOVAs) were conducted to examine variation in risk-taking propensity scores by age, education, element, language, rank, sex, and deployment history. Linear regression analyses were conducted to examine the relationship between risk-taking propensity and health or risk behaviors measured on a continuous scale, while logistic regression analyses (multinomial or binary logistic regression) were conducted to examine the relationship between risk-taking propensity and health or risk behaviors measured on a categorical or nominal scale. In these analyses, recreational risk-taking propensity and health and safety risk-taking propensity were simultaneously entered as independent variables in order to reduce family-wise error and account for intercorrelations among the two. These analyses, however, were not adjusted for demographic covariates, given the exploratory nature of the work.

\section{Results}

\section{Demographic Characteristics}

Mean scores obtained by participants on the DOSPERT re- creational risk-taking propensity and health and safety risk-taking propensity subscales are presented in Table 1 by demographic groupings.

Recreational risk-taking propensity significantly differed according to age group $(F[3,2084]=38.72, p<.001)$, element $(F[2,2080]=5.91, p<.01)$, language $(F[1,2076]=13.16, p$ $<.001)$, $\operatorname{rank}(F[1,2086]=6.95, p<.01)$, and sex $(F[1,2086]$ $=44.24, p<.001)$. Specifically, there was a tendency for recreational risk-taking propensity to be greater among younger respondents, members of the Air Force, those with English as a first official language, officers and men.

Health and safety risk-taking propensity was found to differ according to age group $(F[3,2065]=38.27, p<.001)$, education $(F[2,2040]=4.99, p<.01)$, $\operatorname{rank}(F[1,2067]=17.18, p$ $<.001)$ and sex $(F[1,2067]=141.46, p<.001)$. In line with results regarding recreational risk-taking propensity, health and safety risk-taking propensity was greater among younger respondents and men. However, it was greater among NCMs (rather than officers) and among those without post-secondary education.

\section{Deployment History}

Mean scores by deployment history (i.e., 0, 1, 2, or 3 or more deployments in the past two years) are presented in Table 2. While no differences were observed in recreational risk-taking propensity across deployment history groups, significant differences were observed in health and safety risk-taking propensity $(F[3,2054]=3.11, p<.05)$. An examination of simple effects revealed that health and safety risk-taking propensity was greater among those who were deployed once $(F[1,2056]$ $=4.36, p<.05)$ or twice $(F[1,2056]=5.82, p<.05)$ relative to those who were not deployed in the past two years.

\section{Health and Risk Behaviors}

Diet. Table 3 provides a summary of regression coefficient estimates $(B)$ and corresponding standard errors (SE B) of linear regression analyses predicting eating habits. Results revealed that risk-taking propensity significantly predicted the number of days participants felt too rushed to eat regularly $\left(R^{2}=.02, p\right.$ $<.05)$, skipped breakfast $\left(R^{2}=.06, p<.001\right)$ and skipped lunch $\left(R^{2}=.01, p<.05\right)$ in the past week. While greater health and safety risk-taking propensity was associated with engaging in each of these unfavorable eating behaviors more frequently, greater recreational risk-taking propensity was associated with skipping breakfast less frequently.

Risk-taking propensity was also found to be significantly associated with daily fruit and vegetable servings in a multinomial logistic regression analysis (Nagelkerke $R^{2}=.06, p<.001$ ). While health and safety risk-taking propensity was negatively associated with daily fruit and vegetable servings, recreational risk-taking propensity was positively associated with daily fruit and vegetable servings. Table 4 provides a summary of regression coefficient estimates (B), odds ratios (OR) and corresponding 95\% confidence intervals (CI) resulting from the analysis. Specifically, for every one point increase in score on recreational risk-taking propensity, the odds of consuming 5 to 9 servings increased by $5 \%$ and the odds of consuming 10 or more increased by $7 \%$. For every one point increase in score on health and safety risk-taking propensity, the odds of consuming 5 to 9 servings decreased by $4 \%$ and the odds of consuming 10 
Table 1.

Mean scores and standard errors on measures of recreational and health and safety risk-taking propensity by demographic group.

\begin{tabular}{|c|c|c|c|c|}
\hline \multirow[t]{2}{*}{ Demographic Variable } & \multicolumn{2}{|c|}{$\begin{array}{c}\text { Recreational } \\
\text { Risk-Taking } \\
\text { Propensity }\end{array}$} & \multicolumn{2}{|c|}{$\begin{array}{c}\text { Health and Safety } \\
\text { Risk-Taking } \\
\text { Propensity }\end{array}$} \\
\hline & $M$ & $S E$ & $M$ & $S E$ \\
\hline All Participants & 21.0 & 0.3 & 17.4 & 0.3 \\
\hline \multicolumn{5}{|l|}{ Age } \\
\hline $18-29$ years & $25.6_{\mathrm{a}}$ & 0.7 & $21.2_{\mathrm{a}}$ & 0.6 \\
\hline 30 - 39 years & $21.2_{\mathrm{b}}$ & 0.5 & $17.6_{\mathrm{b}}$ & 0.5 \\
\hline $40-49$ years & $18.3_{\mathrm{c}}$ & 0.5 & $15.3_{\mathrm{c}}$ & 0.4 \\
\hline $50-64$ years & $15.8_{\mathrm{d}}$ & 0.7 & $13.1_{d}$ & 0.6 \\
\hline \multicolumn{5}{|l|}{ Education } \\
\hline Some/Completed Secondary & $20.6_{a}$ & 0.6 & $17.7 \mathrm{a}$ & 0.5 \\
\hline College/Some University & $21.2_{\mathrm{a}}$ & 0.6 & $17.8_{a}$ & 0.4 \\
\hline University Completed & $21.7 \mathrm{a}$ & 0.4 & $16.2_{\mathrm{b}}$ & 0.4 \\
\hline \multicolumn{5}{|l|}{ Element } \\
\hline Air & $22.1_{a}$ & 0.5 & $16.8_{a}$ & 0.4 \\
\hline Sea & $18.9_{\mathrm{b}}$ & 0.7 & $17.7 \mathrm{a}$ & 0.7 \\
\hline Land & $20.9_{\mathrm{c}}$ & 0.5 & $17.9_{a}$ & 0.4 \\
\hline \multicolumn{5}{|l|}{ Language } \\
\hline English & $21.8_{a}$ & 0.4 & $17.7 \mathrm{a}$ & 0.3 \\
\hline French & $19.2_{\mathrm{b}}$ & 0.6 & $16.7 \mathrm{a}$ & 0.5 \\
\hline \multicolumn{5}{|l|}{ Rank } \\
\hline NCM & $20.7 \mathrm{a}$ & 0.4 & $17.8_{a}$ & 0.3 \\
\hline Officer & $22.1_{b}$ & 0.4 & $16.0_{\mathrm{b}}$ & 0.3 \\
\hline \multicolumn{5}{|l|}{ Sex } \\
\hline Men & $21.4_{a}$ & 0.4 & $18.0_{a}$ & 0.3 \\
\hline Women & $18.4_{b}$ & 0.3 & $13.8_{\mathrm{b}}$ & 0.2 \\
\hline
\end{tabular}

Note. Means with subscripts that differ are significantly different at $p<.05$.

Table 2.

Mean scores and standard errors on measures of recreational and health and safety risk-taking propensity by deployment history.

\begin{tabular}{ccccc}
\hline \multirow{2}{*}{$\begin{array}{c}\text { Number of Deployments } \\
\text { in Past Two Years }\end{array}$} & $\begin{array}{c}\text { Recreational } \\
\text { Risk-Taking } \\
\text { Propensity }\end{array}$ & $\begin{array}{c}\text { Health and Safety } \\
\text { Risk-Taking } \\
\text { Propensity }\end{array}$ \\
\cline { 2 - 5 } & $M$ & $S E$ & $M$ & $S E$ \\
\hline 0 & $21.0_{\mathrm{a}}$ & 0.4 & $17.1_{\mathrm{a}}$ & 0.3 \\
1 & $21.3_{\mathrm{a}}$ & 0.5 & $18.2_{\mathrm{b}}$ & 0.4 \\
2 & $21.8_{\mathrm{a}}$ & 1.2 & $19.8_{\mathrm{b}}$ & 1.0 \\
3 or more & $18.6_{\mathrm{b}}$ & 0.9 & $17.1_{\mathrm{a}}$ & 1.1 \\
\hline
\end{tabular}

Note. Means with subscripts that differ are significantly different at $p<.05$.

or more decreased by $8 \%$.

Physical activity. Risk-taking propensity was significantly associated with physical activity (Nagelkerke $R^{2}=.04, p$ $<.001$ ). A summary of results is provided in Table 5 . Specifically, recreational risk-taking propensity was positively associ ated with physical activity such that a one point increase in score on its corresponding measure was associated with a 5\%
Table 3.

Results of multiple regression analyses predicting problem eating habits.

\begin{tabular}{cccc}
\hline & Risk Domain & $B$ & $S E B$ \\
\hline \multirow{2}{*}{ Too Rushed } & Recreational & $<0.01$ & 0.01 \\
& Health and Safety & $0.03^{*}$ & 0.01 \\
\hline \multirow{2}{*}{ Skipped } & Risk Domain & $B$ & $S E$ B \\
Breakfast & Recreational & $-0.03^{* *}$ & 0.01 \\
& Health and Safety & $0.09^{* * *}$ & 0.02 \\
\hline \multirow{2}{*}{ Skipped Lunch } & Risk Domain & $B$ & $S E$ B \\
& Recreational & -0.01 & 0.01 \\
& Health and Safety & $0.02^{*}$ & 0.01 \\
\hline
\end{tabular}

Note. ${ }^{*} p<.05,{ }^{* *} p<.01,{ }^{* * *} p<.001$.

Table 4.

Results of multinomial logistic regression analysis differentiating Regular Force members consuming less than five daily fruit and vegetable servings from those consuming five to nine and ten or more.

\begin{tabular}{ccccc}
\hline \multirow{2}{*}{ Risk Domain } & \multicolumn{2}{c}{5 to 9 Servings } & \multicolumn{2}{c}{$10+$ Servings } \\
\cline { 2 - 5 } & $B$ & OR (95\% CI) & $B$ & OR (95\% CI) \\
\hline Recreational & 0.05 & $\begin{array}{c}1.05 \\
\text { (1.03 - 1.07) }\end{array}$ & 0.07 & $\begin{array}{c}1.07 \\
(1.03-1.12) \\
\text { Health and Safety }\end{array}$ \\
& -0.05 & 0.96 & -0.08 & 0.92 \\
& & $(0.93-0.98)$ & & $(0.88-0.97)$ \\
\hline
\end{tabular}

Note. $\mathrm{CI}=$ confidence interval; $\mathrm{OR}=$ odds ratio.

Table 5.

Results of multinomial logistic regression analysis differentiating physically inactive Regular Force members from those who are moderately active and active.

\begin{tabular}{ccccc}
\hline \multirow{2}{*}{ Risk Domain } & \multicolumn{2}{c}{ Moderately Active } & \multicolumn{2}{c}{ Active } \\
\cline { 2 - 5 } & $B$ & OR $(95 \% \mathrm{CI})$ & $B$ & OR (95\% CI) \\
\hline Recreational & 0.03 & $\begin{array}{c}1.02 \\
(1.00-1.05)\end{array}$ & 0.05 & $\begin{array}{c}1.05 \\
(1.03-1.07) \\
\text { Health and Safety }\end{array}$ \\
& $<-0.01$ & 0.99 & 0.01 & 1.01 \\
& & $(0.96-1.03)$ & & $(0.99-1.04)$ \\
\hline
\end{tabular}

Note. $\mathrm{CI}=$ confidence interval; $\mathrm{OR}=$ odds ratio.

increase in odds of being active relative to inactive. However, health and safety risk-taking propensity was not significantly associated with physical activity.

Safety. Among Regular Force members who ride a bicycle, it was found that the use of a bicycle helmet was significantly associated with risk-taking propensity (Nagelkerke $R^{2}=.14$, $p<.001$ ). In particular, the odds of consistently (i.e., always) using a bicycle helmet while riding a bicycle significantly decreased as a function of health and safety risk-taking propensity but were not related to recreational risk-taking propensity. For every one point increase in score on health and safety risktaking propensity, the odds of consistently using a bicycle helmet decreased by $10 \%$ (Table 6).

Substance use. Risk-taking propensity was significantly associated with the use of both energy drinks (Nagelkerke $R^{2}$ $=.10, p<.001$ ) and performance enhancers (Nagelkerke $R^{2}$ $=.04, p<.001)$. In both cases, the relationship was only significant for health and safety risk-taking propensity, with a one point increase in score associated with an $8 \%$ increase in the odds of using energy drinks and $5 \%$ increase in the odds of using performance enhancers (Table 7). 
Table 6.

Results of binary logistic regression analysis predicting consistent bicycle helmet use.

\begin{tabular}{ccc}
\hline Risk Domain & $B$ & OR $(95 \% \mathrm{CI})$ \\
\hline Recreational & 0.01 & $1.01(0.98-1.03)$ \\
Health and Safety & -0.11 & $0.90(0.88-0.93)$ \\
\hline
\end{tabular}

Note. $\mathrm{CI}=$ confidence interval; $\mathrm{OR}=$ odds ratio.

Table 7.

Results of binary logistic regression analyses predicting energy supplement use in the past year.

\begin{tabular}{cccc}
\hline & Risk Domain & $B$ & OR (95\% CI) \\
\hline \multirow{2}{*}{ Energy Drinks } & Recreational & 0.01 & $1.01(0.99-1.04)$ \\
& Health and Safety & 0.07 & $1.08(1.05-1.11)$ \\
\hline & Risk Domain & $B$ & OR (95\% CI) \\
\hline Performance & Recreational & 0.01 & $1.01(0.98-1.04)$ \\
Enhancers & Health and Safety & 0.05 & $1.05(1.02-1.08)$ \\
\hline
\end{tabular}

Note. $\mathrm{CI}=$ confidence interval; $\mathrm{OR}=$ odds ratio.

The relationship of risk-taking propensity with smoking status was also found to differ across risk domains. While it was significantly associated with smoking status overall (Nagelkerke $R^{2}=.09, p<.001$ ), the odds of being a current or ex-smoker decreased as recreational risk-taking propensity increased (by 3\% and 8\% per one point increase, respectively) and increased as health and safety risk-taking propensity increased (by $8 \%$ and 6\%, respectively), as shown in Table 8.

Risk-taking propensity was significantly associated with having engaged in binge drinking (i.e., consuming six or more drinks on a single occasion) on a monthly basis or more over the past year (Nagelkerke $R^{2}=.19, p<.001$ ). However, this relationship was primarily driven by health and safety risktaking propensity, with the odds of binge drinking increasing by $14 \%$ for every one point increase in score on the subscale (Table 9).

In line with results pertaining to binge drinking, risk-taking propensity was also significantly associated with scores on the AUDIT $\left(R^{2}=.14, p<.001\right)$. Again, the association was only statistically significant for health and safety risk-taking propensity, with greater scores predicting higher AUDIT scores (Table 10).

\section{Discussion}

The aim of the present study was to explore the various correlates of risk-taking propensity in different domains among military personnel. While some of the findings converge with results of previous studies (Kelley et al., 2012; Killgore, 2010a, 2010b), others highlight the value of considering the domainspecificity of risk-taking propensity for providing a more nuanced perspective of its correlates, particularly those related to health and risk behaviors.

\section{Summary of Findings}

Both recreational and health and safety risk-taking propensity were found to differ according to key demographic factors, including age, rank and sex. Younger respondents and men invariably demonstrated greater risk-taking propensity, and these results are consistent with past research. Women appear
Table 8.

Results of multinomial logistic regression analysis differentiating current smokers and ex-smokers from never smokers.

\begin{tabular}{ccccc}
\hline \multirow{2}{*}{ Risk Domain } & \multicolumn{2}{c}{ Current Smoker } & \multicolumn{2}{c}{ Ex-Smoker } \\
\cline { 2 - 5 } & $B$ & OR $(95 \% \mathrm{CI})$ & $B$ & OR (95\% CI) \\
\hline Recreational & -0.03 & $0.97(0.94-0.99)$ & -0.08 & $0.92(0.90-0.95)$ \\
Health and Safety & 0.08 & $1.08(1.05-1.11)$ & 0.06 & $1.06(1.02-1.09)$ \\
\hline
\end{tabular}

Note. $\mathrm{CI}=$ confidence interval; $\mathrm{OR}=$ odds ratio.

Table 9.

Results of binary logistic regression analysis predicting binge drinking behavior (on a monthly basis or more) in the past year.

\begin{tabular}{ccc}
\hline Risk Domain & $B$ & OR (95\% CI) \\
\hline Recreational & $<-0.01$ & $1.00(0.98-1.02)$ \\
Health and Safety & 0.13 & $1.14(1.11-1.18)$ \\
\hline
\end{tabular}

Note. $\mathrm{CI}=$ confidence interval; $\mathrm{OR}=$ odds ratio.

Table 10.

Results of linear regression analysis predicting AUDIT scores.

\begin{tabular}{ccc}
\hline Risk Domain & $B$ & $S E B$ \\
\hline Recreational & 0.02 & 0.02 \\
Health and Safety & $0.18^{* * *}$ & 0.03 \\
\hline
\end{tabular}

Note. ${ }^{*} p<.05,{ }^{* *} p<.01,{ }^{* * *} p<.001$.

to be more risk averse in many situations and contexts, a finding that can at least partly be explained by the fact that they perceive greater risks in most domains (all but the social domain; Weber \& Johnson, 2009). Older adults have been found to be more risk averse than younger adults in some studies, yet the evidence for this effect remains mixed (Weber \& Johnson, 2009).

For other demographic factors, there was notable variation in relationships with risk-taking propensity across domains. While officers demonstrated greater recreational risk-taking propensity, they demonstrated lower levels of health and safety risktaking propensity. Although the specific mechanisms that might explain this observation are unclear, it might account for results of previous analyses pointing to greater participation in physical activity and more consistent use of safety equipment (e.g., bike helmets and seatbelts) among officers (Lee \& Hachey, 2011).

Only recreational risk-taking propensity was found to differ by element and first official language, with higher levels reported by members of the Air Force and those with English as a first official language. One factor that may account for higher levels of risk-taking propensity among members of the Air Force is the fact that one of the scale items assesses one's likelihood of piloting a small plane. Blais and Weber (2006) found a similar difference between English- and French-speaking adult civilians, with English-speaking participants showing greater risk-taking propensity in both the health and recreational domains.

Finally, only health and safety risk-taking propensity was found to differ by educational attainment, with the highest levels reported by those with no university degree. While it would be easy to assume that individuals with lower levels of education might demonstrate more risk-taking propensity in this domain due to lesser awareness of risks, the possible in- 
volvement of other influences should be recognized. For instance, CAF members with lower levels of education may be employed at lower ranks in occupations that require them to be exposed to health and safety risks or to be deployed overseas.

The relationship between deployment history and risk-taking propensity also varied across domains in that health and safety, but not recreational risk-taking propensity differed by deployment history. As was expected, respondents who were deployed one to two times in the past two years demonstrated higher levels of health and safety risk-taking propensity compared to those who were not deployed. On the other hand, those who were deployed three or more times demonstrated similar levels of health and safety risk-taking propensity. Results of a recent study by Kelley et al. (2012) revealed a medium to large effect of deployment on risk-taking propensity. One important difference, however, is that variations were examined by comparing risk-taking propensity before and after deployment rather than comparing risk-taking propensity among service members who have and have not been deployed. Military personnel with different levels of deployment experience may differ on factors other than the number of times they have been deployed, such as their level of health. The "healthy warrior" effect, for instance, refers to the tendency for military personnel who have been deployed to demonstrate better health than their non-deployed counterparts, in part due to screening and selection processes (Haley, 1998). Similarly, the fact that those who were deployed three or more times demonstrated similar levels of health and safety risk-taking propensity than those who had not been deployed might have related to the need to have extremely good health in order to be able to go on multiple deployments and the fact that any propensity to take health and safety risks would have compromised health.

Analyses of the relationships between risk-taking propensity in both domains and various risk behaviors yielded an interesting pattern of results. As expected, greater health and safety risk-taking propensity was associated with a number of healthcompromising behaviors, including poor eating habits (i.e., skipping meals, lower fruit and vegetable consumption), lesser use of bicycle helmets, and greater use of various substances (i.e., energy drinks, performance enhancers, tobacco and alcohol). Given that some of the items used to assess health and safety risk-taking propensity related to alcohol consumption and motorcycle helmet use, its relationship with bicycle helmet use and alcohol consumption may not be entirely remarkable. Still, it is reiterated that the purpose of these items is to assess one's propensity to engage in these behaviors, which is distinct from an individual's actual engagement in them.

Contrary to expectations, recreational risk-taking propensity was associated with a number of health-enhancing behaviors. Specifically, respondents who reported greater recreational risk-taking propensity demonstrated better eating habits (i.e., not skipping lunch, higher fruit and vegetable consumption), higher levels of physical activity, and lower odds of being a current or ex-smoker. Such findings recall the distinction that has been made between behavioral immunogens, as behaviors that promote health and prevent disease, and behavioral pathogens, as behaviors that impair health and increase the risk of disease (Matarazzo, 1984). Having focused on risk behaviors, such as alcohol use and fighting, much of the work on risktaking propensity in military personnel has addressed the latter. Yet, the current findings suggest that there may be value in considering other types of behavioral outcomes, as these may result from different factors and processes.

\section{Limitations}

On the whole, findings bring to light noteworthy variations in the potential outcomes of risk-taking propensity in different domains. However, some important limitations are noted. First, while a causal relationship may be assumed between risk-taking propensity and the health and risk behaviors, the direction of these relationships may not be inferred due to the cross-sectional nature of the study.

A second limitation is the fact that only a small set of DOSPERT subscales were considered in the present study. In addition to including measures of risk-taking propensity in different risk domains (health and safety, recreational, financial, ethical and social domains), the original DOSPERT includes measures to assess perceptions of risk in these domains (Blais \& Weber, 2009). Having considered both perceptions and behavioral intentions related to risks in all of the domains could have provided a more detailed perspective of the mechanisms that might account for the relationship between risk-taking propensity and health and risk behaviors.

\section{Implications for Theory and Research}

Previously, it was recognized that a certain degree of risktaking may be beneficial in the military context (Momen et al., 2010). Specifically, Momen et al. (2010, p. 130) noted, "[s]ome risk-takers are more impulsive and are more likely to experience preventable negative consequences as result of their thrill- seeking propensity. Some risk-takers, on the other hand, go through a process of deliberation where they contemplate before taking risks. These individuals are more likely to experience positive consequences for their risk-taking behavior". Recognizing the potential benefits of readiness to accept risks, some military organizations have considered sensation seeking as one element of recruiting campaigns (Parmak, 2011; Sackett \& Mavor, 2004). However, a greater propensity to take risks may pose problems if it leads to behaviors that may compromise health. While analyses were exploratory in nature, results demonstrated a fair degree of consistency in support of the role of recreational risk-taking propensity in health-enhancing behavior and the role of health and safety risk-taking propensity in health-compromising behavior in the present study. Additional research in which the domain-specificity of risk-taking propensity is considered could bring us closer to understanding which specific aspects of risk-taking propensity are desirable and which ones are not.

A common feature of items used to assess recreational risk-taking propensity is their focus on the propensity for engaging in extreme sports or activities that would require skill, knowledge or preparation. While these activities entail a certain degree of risk, success in these activities also requires participants to be in top shape. In a qualitative study of extreme sport practitioners, it was revealed that the physical and mental challenge posed by extreme sports was an important factor in individuals' reasons for engaging in them (Willig, 2008). For some, improving their skills and gaining experience with the sport generated a sense of mastery. In order to develop their capabilities and further push themselves, athletes had to be disciplined and self-aware. Hence, the psychological processes that increase individuals' propensity for recreational risk-taking may, in some way, overlap with those that compel them to monitor 
and think about their behaviors more closely. This could be interpreted as a form of careful deliberation and contemplation, which some have argued may enable more effective risk-taking and positive outcomes (Momen et al., 2010), and could account for why recreational risk-taking propensity was associated with health-enhancing behaviors. While further research is necessary to fully understand the psychological processes involved in this relationship, it could be worthwhile for military organizations to target individuals with a specific propensity for recreational risk-taking in military recruitment campaigns rather than a broader sensation seeking temperament.

As a rule, items used to assess health and safety risk-taking propensity focused on the propensity for engaging in activities that may threaten individuals' health or safety. The relationship between health and safety risk-taking propensity in risk behavior was therefore not surprising. Kelley et al. (2012) noted that risk-taking propensity may not only put the health and safety of individuals and their families in jeopardy, it may also have a detrimental impact on operational readiness. Given the potential effects of deployment on health and safety risk-taking propensity, it could be worthwhile to assess the value of incorporating discussions on the impacts of deployment into pre-deployment training and education. Raising awareness about possible increases in risk-taking among military personnel upon their return from deployment and the implications for health and safety could encourage service members and their families to monitor and regulate their behavior. Furthermore, the possible link between risk-taking propensity and overall well-being should be addressed in these discussions to ensure that emotional needs are not overlooked.

\section{Next Steps}

A major limitation of the present analyses is their cross-sectional nature. Measures of risk-taking propensity will be administered as part of another survey in the CAF - the Recruit Health Questionnaire- which serves as a baseline health monitoring tool administered in the early stages of basic military training (Whitehead, Lee, \& McCreary, 2012). In future work, it will thus be possible to conduct prospective analyses to examine the predictive validity of risk-taking propensity for health and risk behaviors, as well as other outcomes, such as injuries or work performance. Future research using a longitudinal study design will provide a better platform for determining whether risk-taking propensity does change as a function of military experiences, such as training or deployment, and whether it plays a role in other outcomes, such as injury.

As well, additional work could address the possible role of risk-taking propensity in the performance of military duties. While some aspects of risk-taking propensity may be negatively associated with behavioral health, they could still play a role in the successful performance of military duties, particularly those involving a high degree of risk. It may be useful to consider the nature of the relationship between risk-taking propensity and performance of military duties in addition to its relationship with behavioral health to arrive at a more balanced understanding of the implications of risk-taking propensity for military organizations.

\section{Conclusion}

Although analyses were exploratory in nature, results provide support for the role of recreational risk-taking propensity in promoting health-enhancing behaviors and the role of health and safety risk-taking propensity in promoting health-compromising behaviors. Ultimately, these observations bring us closer to understanding which specific aspects of risk-taking propensity may be desirable and which ones may be undesirable. Given that a fair degree of risk-taking may be beneficial in the military context (Momen et al., 2010), these findings raise the question of whether it may be beneficial to target individuals demonstrating more adaptive forms of risk-taking propensity (such as recreational risk-taking propensity) rather than those with a broader sensation seeking nature in military recruitment campaigns. Additional longitudinal research on the relationships of risk-taking propensity in different domains with injury or performance in military duties (in addition to health and risk behaviors) could help shed light on this issue. Longitudinal research in this area would also be fruitful to better understand how risk-taking propensity may change over time, both as a normal part of the aging process and as a function of military experiences, and how it may influence health.

\section{Acknowledgements}

The authors would like to thank Dr. Jeff Whitehead for granting access to the 2008/9 Regular Force Health and Lifestyle Information Survey dataset, as well as the various reviewers for their critical feedback on earlier drafts of this manuscript.

\section{REFERENCES}

Babor, T. F., Higgins-Biddle, J., Saunders, U., \& Monteiro, M. (2001). The Alcohol Use Disorders Identification Test: Guidelines for use in primary health care. Geneva, Switzerland: World Health Organization.

Bell, N. S., Amoroso, P. J., Wegman, D. H., \& Senier, L. (2001). Proposed explanations for excess injury among veterans of the Persian Gulf War and a call for greater attention from policymakers and researchers. Injury Prevention, 7, 4-9.

Blais, A.-R., \& Weber, E. U. (2009). The Domain-Specific Risk Taking Scale for adult populations: Item selection and preliminary psychometric properties (DRDC Toronto TR 2009-203). Toronto, Ontario: Defence Research and Development.

Bray, R. M., Pemberton, M. R., Lane, M. E., Hourani, L. L., Mattiko, M. J., \& Babeu, L. A. (2010). Substance use and mental health trends among U.S. military active duty personnel: Key findings from the 2008 DoD Health Behavior Survey. Military Medicine, 175, 390-399.

Cherpitel, C. J. (1993). Alcohol, injury and risk taking behavior: Data from a national sample. Alcoholism: Clinical and Experimental Research, 17, 762-766.

Cherpitel, C. J. (1999). Substance use, injury, and risk-taking dispositions in the general population. Alcoholism: Clinical and Experimental Research, 23, 121-126.

Donovon, J. E., \& Jessor, R. (1985). Structure of problem behavior in adolescence and young adulthood. Journal of Consulting and Clinical Psychology, 53, 890-904.

Garriguet, D. (2009). Diet quality in Canada. Health Reports, 20, 1-12.

Haley, R. W. (1998). Bias from the "health warrior effect" and unequal follow-up in three government studies of health effects of the Gulf War. American Journal of Epidemiology, 148, 315-323.

Hanoch, Y., Johnson, J. G., \& Wilke, A. (2006). Domain-specificity in experimental measures and participant recruitment: An application to risk-taking behaviour. Psychological Science, 17, 300-304.

Harrison, J. D., Young, J. M., Butow, P., Salkeld, G., \& Solomon, M. J. (2005). Is it worth the risk? A systematic review of instruments that measure risk propensity for use in the health setting. Social Science 
\& Medicine, 60, 1385-1396.

Hooper, T. I., DeBakey, S. F., Bellis, K. S., Kang, H. K., Cowan, D. N., Lincoln, A. E., \& Gacksetter, G. D. (2006). Understanding the effect of deployment on the risk of fatal motor vehicle crashes: A nested case-control study of fatalities in Gulf war era veterans, 1991-1995. Accident Analysis \& Prevention, 38, 518-525.

Jacobson, I. G., Ryan, M. A. K., Hooper, T. I., Smith, T. C., Amoroso, P. J., Boyko, E. J., Gacksetter, G. D., Wells, T. S., \& Bell, N. S. (2008). Alcohol use and alcohol-related problems before and after military combat deployment. JAMA, 300, 663-675.

Jessor, R., Donovon, J. E., \& Costa, F. M. (1991). Beyond adolescence: Problem behavior and young adult development. New York: Cambridge University Press.

Kelley, A. M., Athy, J. R., Cho, T. H., Erickson, B., King, M., \& Cruz, P. (2012). Risk propensity and health risk behaviors in U.S. army soldiers with and without psychological disturbances across the deployment cycle. Journal of Psychiatric Research, 46, 582-589.

Kelley, A. M., Killgore, W. D. S., Athy, J. R., \& Dretsh, M. (2010). Risk propensity, risk perception, and sensation seeking in U.S. army soldiers: A preliminary study of a risk assessment task battery (USAARL Report No. 2010-02). Fort Rucker, AL: U.S. Army Aeromedical Research Laboratory.

Killgore, W. D. S., Castro, C. A., \& Hoge, C. W. (2010a). Preliminary normative data for the Evaluation of Risks Scale-Bubble Sheet Version (EVAR-B) for large-scale surveys of returning combat veterans. Military Medicine, 175, 725-731.

Killgore, W. D. S., Kelley, A., \& Balkin, T. J. (2010b). So you think you're bulletproof: Development and validation of the Invincibility Beliefs Index (IBI). Military Medicine, 175(7), 499-508.

Killgore, W. D. S., Cotting, D. I., Thomas, J. L., Cox, A. L., McGurk, D., Vo, A. H., Castro, C. A., \& Hoge, C. W. (2008). Post-combat invincibility: Violent combat experiences are associated with increased risk-taking propensity following deployment. Journal of Psychiatric Research, 42, 1112-1121.

Killgore, W. D. S., Vo, A. H., Castro, C. A., \& Hoge, C. W. (2006). Assessing risk propensity in American soldiers: Preliminary reliability and validity of the Evaluation of Risks (EVAR) Scale-English version. Military Medicine, 171, 233-239.

Lee, J. E. C., \& Hachey, K. K. (2011). Descriptive analyses of the Recruit Health Questionnaire: 2007-2009 (DGMPRA TM 2011-028). Ottawa, Ontario: Director General Military Personnel Research and Analysis, Department of National Defence.

MacCrimmon, K. R., \& Wehrung, D. A. (1986). Taking risks: The management of uncertainty. New York: Free Press.

MacCrimmon, K. R., \& Wehrung, D. A. (1990). Characteristics of risk taking executives. Management Science, 36, 422-435.

Matarrazo, J. D. (1984). Behavioral immunogens and pathogens in health and illness. In C. J. Scheier, \& B. L. Hammonds (Eds.), Health and behaviour. Washington, DC: American Psychological Association.

Momen, N., Taylor, M. K., Pietrobon, R., Gandhi, M., Markham, A. E., Padilla, G. A., Miller, P. W., Evans, K. E., \& Sander, T. C. (2010). Initial validation of the Military Operational Risk Taking Scale (MORTS). Military Psychology, 22, 128-142.

North Atlantic Treaty Organisation (NATO) Research and Technology Organisation (RTO) Task Group 164 (2012). Psychological aspects of deployment and health behaviors (RTO Technical Report TRHFM-164). Neuilly, France: NATO, RTO.

Parmak, M. (2011). Should all soldiers be sensation seekers? The role of personality in the context of operational deployments. Doctoral dissertation. Leuven, Belgium: University of Leuven. http://www.ksk.edu.ee/wp-content/uploads/2011/01/Dissertation Me rle_Parmak.pdf

RTI International (2006). Health behavior and health promotion. In Department of Defense, Survey of Health Related Behaviors among Active Duty Military Personnel (pp.175-194). Research Triangle Park, NC: Author.

Sackett, P. R., \& Mavor, A. S. (2004). Evaluating military advertising and recruiting: Theory and methodology (National Research Council [US] Committee on the Youth Population and Military Recruitment-Phase 11. Board on Behavioral, Cognitive and Sensory Sciences, Division of Behavioral and Social Sciences and Education). Washington, DC: The National Academies Press.

Schoemaker, P. J. H. (1990). Are risk-preferences related across payoff domains and response modes? Management Science, 36, 1451-1463.

Statistics Canada (2001). Canadian Community Health Survey (CCHS) questionnaire for cycle 1.1. Ottawa, Ontario: Author. http://www23.statcan.gc.ca/imdb-bmdi/pub/instrument/3226 Q1 V1 -eng.pdf

Statistics Canada (2005). Canadian Community Health Survey (CCHS) cycle 2.1 public use microdata file (PUMF) derived and group variable specifications. Ottawa, Ontario: Author.

http://www23.statcan.gc.ca/imdb-bmdi/document/3226_D5_T9_V2eng.pdf

Thomsen, C. J., Stander, V. A., McWhorter, S. K., Rabenhorst, M. M., \& Milner, J. S. (2011). Effects of combat deployment on risky and self-destructive behavior among active duty military personnel. Journal of Psychiatric Research, 45, 1321-1331.

Weber, E. U., Ames, D., \& Blais, A.-R. (2005). How do I choose thee? Let me count the ways: A textual analysis of similarities and differences in modes of decision making in the USA and China. Management and Organization Review, 1, 87-118.

Weber, E. U., Blais, A.-R., \& Betz, E. (2002). A domain-specific risk-attitude scale: Measuring risk perceptions and risk behaviors. Journal of Behavioral Decision Making, 15, 263-290.

Weber, E. U., \& Johnson, E. J. (2009). Mindful judgment and decision making. Annual Review of Psychology, 60, 53-85.

Weber, E. U., \& Lindemann, P. G. (2007). From intuition to analysis: Making decisions with our head, our heart, or by the book. In $\mathrm{H}$. Plessner, C. Betsch, \& T. Betsch (Eds.), Intuition in judgment and decision making (pp. 191-208). Mahwah, NJ: Lawrence Erlbaum.

Whitehead, J., \& Hawes, R. A. (2010). Canadian Forces Health and Lifestyle Information Survey 2008/9 Regular Force Report. Ottawa, Ontario: Canadian Forces Health Services Group, Department of National Defence.

Whitehead, J., Lee, J. E. C., \& McCreary, D. (2011). Prospective Recruit Health Questionnaire (Pre Health Q) DRDC Human Research Ethics Committee Submission (Protocol \# L-408A), Unpublished document.

Willig, C. (2008). A phenomenological investigation of the experience of taking part in "extreme sports". Journal of Health Psychology, 13, 690-702.

Zamorski, M. A., \& Kelley, A. M. (2012). Chapter 5-Risky driving behaviour. In North Atlantic Treaty Organisation (NATO) Research and Technology Organisation (RTO) Task Group 164, Psychological aspects of deployment and health behaviors (RTO Technical Report TR-HFM-164). Neuilly, France: NATO, RTO. 